\title{
Photography as a tool of alienation: Aura
}

\author{
Murat Germen \\ Sabanci University / Visual Arts and Communication Design Program \\ Sabanci University, FASS, Orhanli, Tuzla, 34956 Istanbul, Turkey \\ muratgermen@sabanciuniv.edu http://www.muratgermen.com
}

\begin{abstract}
Regular photographical imaging records volumetric planes with smooth surfaces. The reason is the camera's deficiency in perceiving and documenting the visual richness of 'persuasive' details in life. HDR imaging methods used in creating this artwork series titled Aura helped making invisible organism-like textures emerge and point to the notions of decay and symbiosis.
\end{abstract}

One of the main objectives of this series of artworks is to facilitate the emergence of the experiential visual complexity between the animate and inanimate that is otherwise not possible to record. The latent aura of textural presences around us is not always noticeable easily since we tend to consume things too fast. With the rich textures achieved after high-dynamic-range-imaging (HDRI) procedures, a new symbiotic painterly visual relationship between biological (humans) and non-biological (space) was intended.

In addition, the paper will focus on photography rather as a tool of personal world making, instead of photography as witnessing. During the process of unfolding this practice; notions of superimposition, palimpsest, painting vs. photography, truth, photography as an apparatus to provoke defamiliarisation will be covered. The final aim is to confirm photography as a visual language that enriches and transforms human perception.

Photography. Construct. Truth. Ambiguity. Representation. Defamiliarisation. Palimpsest. Superimposition. Disappearance. Ordinariness. Aura. Layering.

\section{INTRODUCTION}

Photography is one of the creative fields at which technological advances influence artistic expression the most. The ease of manipulation brought by software and extra features available in cameras made artists (using photography as an articulation tool) reconsider their visions, themes, narration, syntax and ways of sharing their artwork. Photography sharing sites like Flickr, which expedite encounters of various individuals from different cultures, help in changing the perception of the much vital notion of time and enable artists to get faster feedback, revelation, exposure and layering of information to be conveyed.

While some photographers, who are deeply obsessed with analogue processes, deny digital technology, it is quite obvious that artists, who are aware of the complexity and particular advantages that this technology brings, indeed end up with a novel aesthetics of photography. In addition to the regular montage and collage methods remaining from the old analogue days, digital imaging techniques allow artists to work with notions like augmented perception, chronophotography, subreal encounters, pictorialism, palimpsest-like superimposition, interlacing, simplification / minimisation, creation of new worlds, delusion, synthetic realism / artificiality, appropriation.

\section{SUPERIMPOSITION - NOTION OF PALIMPSEST}

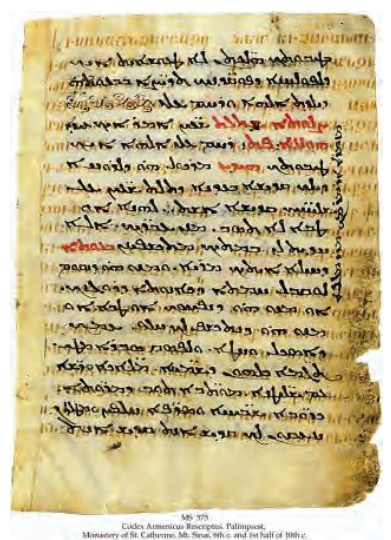

Figure 1: A palimpsest was created when an old vellum was erased and recycled and a new text was placed on. Image captured from

http://analepsis.wordpress.com/2008/04/24/this-is-apalimpsest/ on 6 December 2008 
The painterly effect obtained as the result of the digital superimposition process reminds us of the very analogue concept of palimpsest (Greek 'palin', again; 'psëstos' scraped) which is a re-used papyrus or parchment manuscript in which the original text has been washed or scraped off and a new one substituted. The modern version of this archaic surface of knowledge which allows accumulation of information is the Photoshop canvas, where you can completely cover a layer behind yet still make some details emerge from beneath. This possibility of layering various data from different sources on one plane is a more complex form of the good old analogue collaging \& montaging methods and enables artists to reach a richer expression through superimposed pluralities.

The only way of obtaining visual superimpositions is not layering various photographical planes on to one plane. 'Also very common in photographs are disjunctions caused by reflections. [...] While reflections in mirrors create discontinuities, reflections in glass can create an intermingling of spaces. [...] This prevalence of reflections in photographs is matched by a prevalence in photorealist paintings, but in each medium the effects are very different. This is not just because the image of reflection is generally flatter, more broadly defined, and more opaque in paint.' (Savedoff, 2000, p. 105). This sort of optically obtained superimposition is unique and yields a different accumulative entity as compared to layering of multiple images in the digital environment. When these two analogue and digital visual layerings are combined, it is possible to end up with some renderings of the 'real' world almost impossible to decipher volumetrically.

The Aura series consists of photo-composites obtained with the combination of Photoshop and Photomatix Pro in order to perform HDR imaging. Four or more photographs from the same angle are used for each of the plates from the series. All multiple-photo groups, recorded inanimate objects still, yet animate subjects in different positions / movements due to passage of time and slow shutter speeds. Superimposition of four photographs resulted with the particular aesthetics of the constant appearance of immobile objects and the dynamic intricacy as a consequence of layered mobile subjects. The aim in multiplying the photographical renderings of these mobile subjects is to reach a similar complicated result to the above mentioned notion of merging reflective analogue visual data with its reflexive digital one.

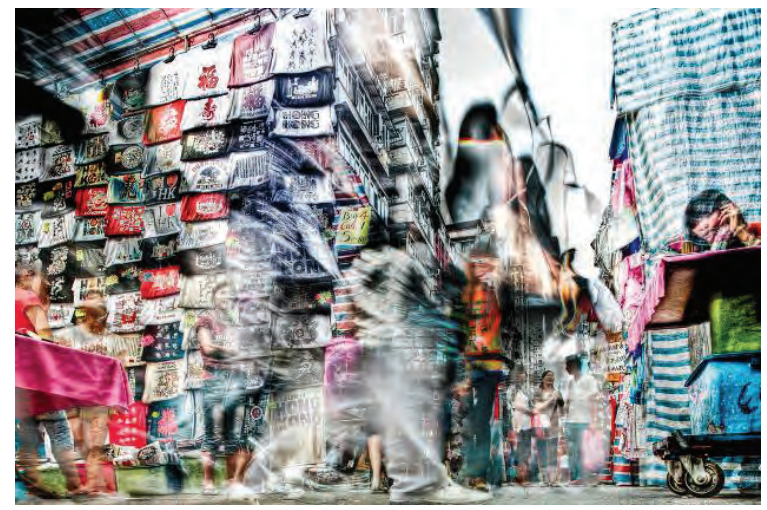

Figure 2: Aura \#16, Hong Kong, Murat Germen, 2009

\section{SUPERIMPOSITION OF CONTEXTS: THE CONCEPT TEXT OF THE AURA SERIES}

The concept text of the Aura series does not only concentrate on the visual complexity of the world surrounding us. There is also a social concern to be expressed only through concept text; so the presence of the concept text is essential. As Barthes states in his book titled Image-Music-Text, 'the structure of the photograph is not an isolated structure; it is in communication with at least one other structure, namely the text - title, caption or article.' (Barthes, 1978, p. 16). The following paragraphs constitute the departure point of the series and explain why photographs were taken by superposing the different contexts: museums / galleries and market places...

In galleries, museums, art fairs or bazaars, markets, items on display are usually preferred if they have a certain 'aura'. This aura, beyond a pristine 'beauty' of the self, may depend on current trends that are vogue, the identity of the particular exhibit venue, the specific person or the brand that exhibits, the arbitrary daily mood of the audience / buyers, the symbiotic relationship between who exhibits and promotes with positive critique, and sometimes the exhibitor's statement and the perception of this statement by audience / buyers. What renders something beautiful is not always the inner self, something can easily be rendered 'beautiful' externally...

This series of artworks, focusing on the difference between the intrinsic soul and extrinsic perception subsidiary to conditions, was created in galleries, museums and market places in Paris, Bologna, Hong Kong, London and Istanbul in 2009. The work is conceived as a reminder and critique of the everpresent but recently much-peaked 'market economy' climate and approach, concealed with various awareness arguments in artists' statements. When it is time for important art events, the delusional presence of 'wild' parties, discourses, allegations, lobbying and pathetic self- 
promotion efforts in exhibition openings, the pursuit for sponsors and sponsors' hegemonic steering, the making of artists race with each other on auction prices, the focus and the following press coverage on celebrities at the openings as opposed to artworks themselves, draws much attention. These astonishing demeanours possibly point to the fact that art has lost its freedom, sits right in the middle of the system it allegedly criticises and finally disingenuously exalts the system. In the presence of commercial art milieu, it seems there has not remained much difference between art venues and shopping malls. Aura series can be taken as a study created after the desire of having artworks independent of peripheral conditions and gaining their inherent value...

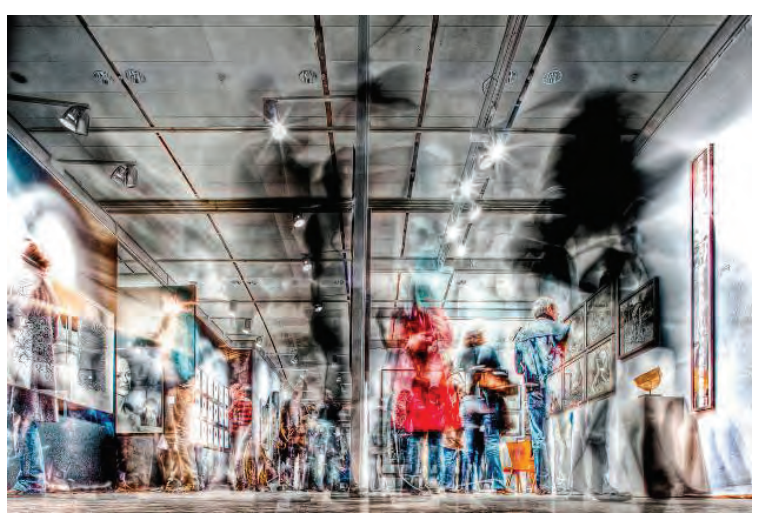

Figure 3: Aura \#22, Paris, Murat Germen, 2009

\section{RELATIONSHIP BETWEEN PAINTING AND PHOTOGRAPHY}

There is a never-ending relationship between photography and painting. When photography was invented, it took painting's function of recording history and was more trusted as a documentary tool since it witnessed experiences more realistically than paintings, which are actually constructs from scratch. Sometime after, photography proved its independence and stopped being seen as pure evidence. This is when it found the opportunity to act like painting and be taken as an apparatus of fiction. This new relationship gave birth to 'pictorial' photographs that emulated optical qualities of paintings, which in turn paved the path to hyper-realistic paintings that are easily mistaken for photographs.

Technological advances in computers' image processing capabilities, the amazingly rich variety in image editing software allow for utmost manipulation in photography and seem to weaken the credibility of photography as evidence. This is how photography finds the opportunity to get rid of the very heavy weight of representing the truth for the public and to begin representing the photographer; i.e. the self, just like the painter.
Barthes speaks of the painterly potential in photography as a means of considering it as art: 'For if one can talk of aestheticism in photography, it is seemingly in an ambiguous fashion: when photography turns into painting, composition or visual substance treated with deliberation in its very material 'texture', it is either so as to signify itself as 'art' (which was the case with the 'pictorialism' of the beginning of the century) or to impose a generally more subtle and complex signified than would be possible with other connotation procedures' (Barthes, 1978, p. 24).

Pictorialism of old days is nowadays replaced by the digital alchemy of two different forms of images: photography and 3D synthesised images. 'Computerised design systems that flawlessly combine real photographed objects and objects synthesised by the computer' (Manovich, 1995). The photographic image obtained by witnessing 'what is there' can easily be turned into an image recreated 'from scratch' and made to express 'what is here', i.e. the creator's mind. As William Mitchell claims 'a digital image is radically different [than an analogue counterpart] because it is inherently mutable: 'the essential characteristic of digital information is that it can be manipulated easily and very rapidly by computer. [...] Computational tools for transforming, combining, altering, and analysing images are as essential to the digital artist as brushes and pigments to a painter.' [...] Furthermore, in a digital image, the essential relationship between signifier and signified is one of uncertainty' (Manovich, 1995). This uncertainty offers the possibility for multiple readings of the artworks and is much appreciated by most of the artists.

The association of photography with the so-called reality seems to bind its expressive promises but the above mentioned ambiguity of digital image in the relationship between signifier and signified takes it beyond the boundaries: 'Unlike paintings, photographs are seen as having a special connection with reality, and this gives the transformations of photography a compelling force and surreal power unavailable to painting. [...] This difference between painting and photography can also he observed in the comparison of animated and live film' (Savedoff, 2000, p. 7). In painting the signifier has to be defined as much realistically as possible since paintings re taken as constructions resulting from the artist's imagination. But in photography which records the world as seen, the realistic rendering of the signifier / phenomena is not of prime importance and this is how it is possible to focus on the meaning / presence of the signified. As Barbara Savedoff puts it, 'the difficulty in painting is to make the image seem alive. Photography, though, has a different starting point. Because it provides a direct record of an animate 
being, it can be a triumph of photographic art to make us see that person in a new way' (Savedoff, 2000, p. 42).

Barthes (1982, pp. 76-77) says 'painting can feign reality without having seen it' in his famous 'Camera Lucida'; photography on the contrary, can pretend reality after having seen it. This pretentious reality is actually the photographer's subjective 'framed' reality and is sometimes presented as objective. Despite this subjectivity and 'false' objectivity, photography can keep still its documentary touch as 'digital manipulation might seem particularly conducive to photographic transformation, since very complicated alterations can be achieved without destroying the image's documentary feel' (Savedoff, 2000, p. 125).

\section{PHOTOGRAPHY AND RENDERING OF TRUTH}

Photography for some is the factual manifestation of reality. Yet, the illusion of a single reality, is criticised by V. Flusser (2000): 'The [observer] trusts [technical images] as he trusts his own eyes. If he criticises them at all, he does so not as a critique of image, but as a critique of vision; his critique is not concerned with their production, but with the world 'as seen through' them. Such a lack of critical attitude towards technical images is dangerous in a situation where these images are about to displace texts. [It] is dangerous because the 'objectivity' of the technical image is a delusion. They are, in truth, images, and as such, they are symbolical...' Some artists take this critical attitude to an extreme to defy 'Reality' and create a new synthetic reality.

As William Mitchell states in his The Reconfigured Eye: Visual Truth in the Post-Photographic Era, 'because of the difficulty involved in manipulating them, photographs were comfortably regarded as causally generated truthful reports about things in the real world.' Yet developments in digital image processing made manipulation easier than before and available to a lot of people, and not only to experts. The above mentioned critical attitude to defy reality and ease in image manipulation led to new tendencies of creating personal worlds. Mark Kingwell asserts that 'photographs are not multiple depictions of some single reality, waiting out there to be cornered and cropped, and somehow regulating, even in the cornering and cropping, how I what the image means. Rather, photographs offer multiple meanings. The presented image is not a reflection, or even an interpretation, of singular reality. It is, instead, the creation of a world.' (Kingwell, 2006) This trend should not be seen as a 'dangerous' lead in the present day visual culture, since photographs have actually never been autonomous entities but have always depended on specific local / contextual historic, social, political and cultural interpretations by people producing and consuming them.

When you are conscious of this potential of photography, individuals, institutions, and nations, you should start using it as an illustrative tool in constructing reality as opposed to representing reality, since photography can transform the way we see representations. 'Media, being in between the segments of the society, have a certain influence in the construction of social reality. Media put issues on the agenda, provide information about facts and events, and offer a cognitive framework for society's interpretation' (Kempf, 2003, pp. 18-19). 'Construct' is a temporary process that exists for a while and finally transforms itself into an end 'product': A building, a culture, a society, an idea, a freedom, a dogma, etc... Not only buildings and structures are built; the major components that constitute the spine of the society we live in, such as tradition, culture, and identity can also be constructed.

\section{PHOTOGRAPHY AS AN APPARATUS TO PROVOKE DIS-APPEARANCE, AMBIGUITY AND DEFAMILIARISATION}

Life is so full of bizarrenesses that the famous saying 'truth is stranger than fiction' was coined. Consequently, conveying 'real' appearances through photographs, striving for certainty in image making or communicating familiarities may not always turn as 'resourceful' as expected. Instead, defamiliarisation of the subject to be presented in the eyes the audience offers alternative ways of communicating with them. Defamiliarisation is a strategy used especially by radical modernist artists in various fields to challenge our habitual ways of seeing and understanding, allowing or forcing us to 'see afresh'. The key technique for artists attempting to 'make it strange' or to create an 'alienation effect,' as defamiliarisation is also called, is to 'foreground' the various devices of artistic language in such a way as to bring attention to the language itself and prevent habitual ways of seeing and reading. Pioneered by the Russian Formalists of the early twentieth century, defamiliarisation was meant to disturb life's habitual ideologies (Patin, and McLerran, 1997, p. 30). Viktor Shklovsky introduced the concept of defamiliarisation in his seminal essay, Art as Device (often translated as Art as Technique) and claimed that art defamiliarises objects by presenting them as if seen for the first time and it removes them from the automatism of human perception.

When a photograph defamiliarises, it is as though something new to the perception is being disclosed 
through ambiguity and the resulting observation can turn out to be highly stimulating. This approach makes familiar appearances disappear and allows us to focus on the notion of 'dis-appearance' which can be described as the depiction of the subject / object / scene 'as experienced and / or felt' and not only 'as seen'.

\section{CONCLUSION}

My artist's statement will clarify my position as a conclusion. Photography is an opportunity for me to find things people ignore and bring them forward to make people reconsider their ideas. I am not interested in extraordinary things, since they are always covered and receive more attention due to mankind's unending interest in celebrities, fame, sensation... I try to concentrate more on ordinary things and catch possible latent extraordinariness in regularity. It is easy to take ordinary photographs of extraordinary things but more challenging to take extraordinary photographs of ordinary things. It is possible to say I tend to concentrate on extracting beauty out of the ordinary. I attempt to defamiliarise ordinariness, render it ambiguous by alienating it from its familiar context and finally make people 'see it afresh.'

Photography records the surface information, where one can only depict the exterior features of objects (colour, texture, shape, etc.) and the resulting visual representation cannot incorporate the internal condition / content / soul. This is why I additionally aim to make photographs that carry the many traces of time, multiple dimensions of space and finally create photographs usually invisible to the naked eye. The basic idea is to form a personal visual accumulation through time and space that supposedly give us more insight/clues than a single photograph. I see multi-layered photography / chronophotography as gates to augmented perception, surreal encounters, creation of new worlds and self-appropriation, since I do not believe in ultimate objectivity in photography and 'Truth' with the capital T. Personal delineations of temporary yet experienced smaller realities are truer than imposed institutional 'realities'. The key is reflecting the inner world with a genuine, idiosyncratic way: 'Do not follow the suggested agenda / trend, do your own thing...'

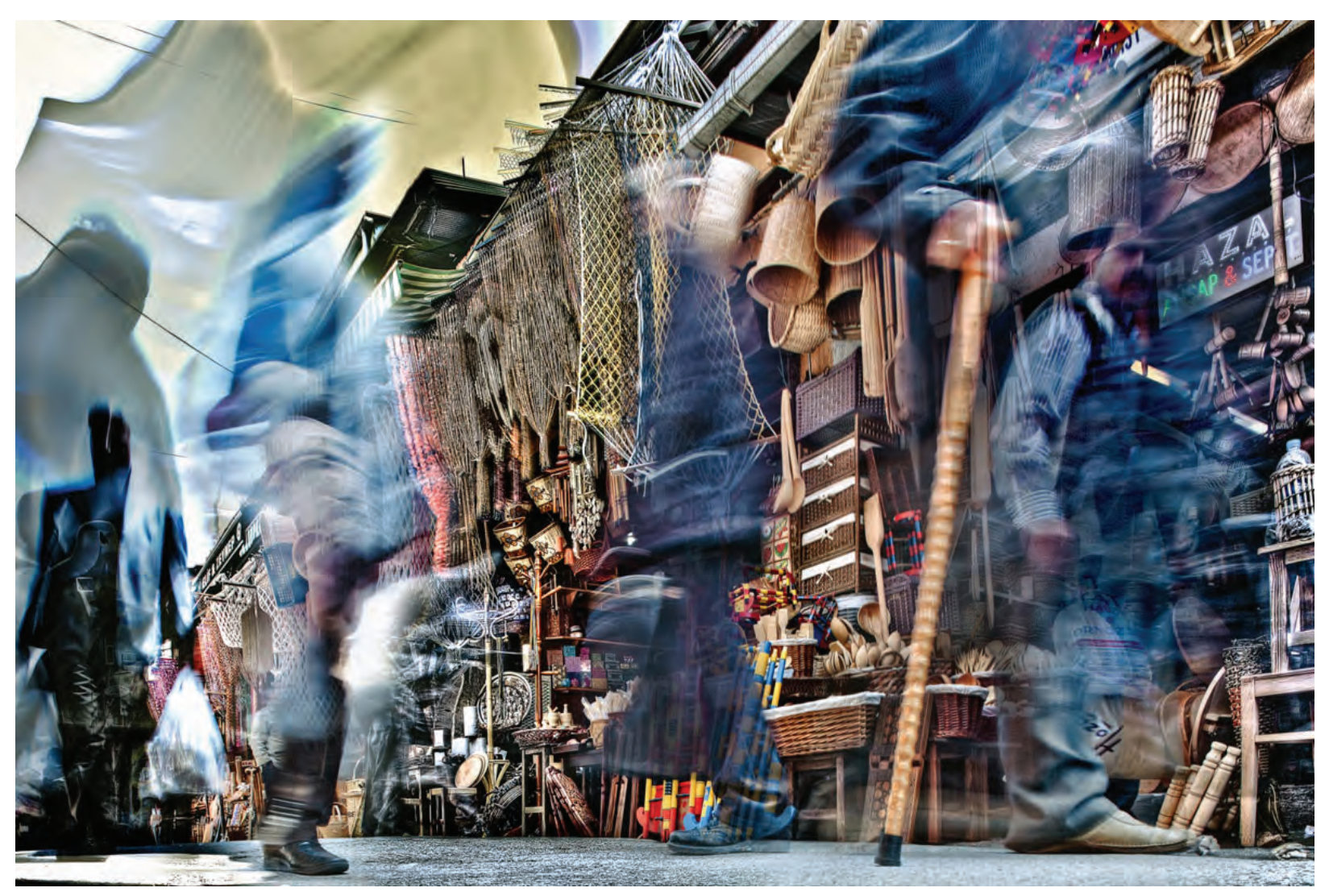

Figure 4: Aura \#4, Istanbul, Murat Germen, 2009 


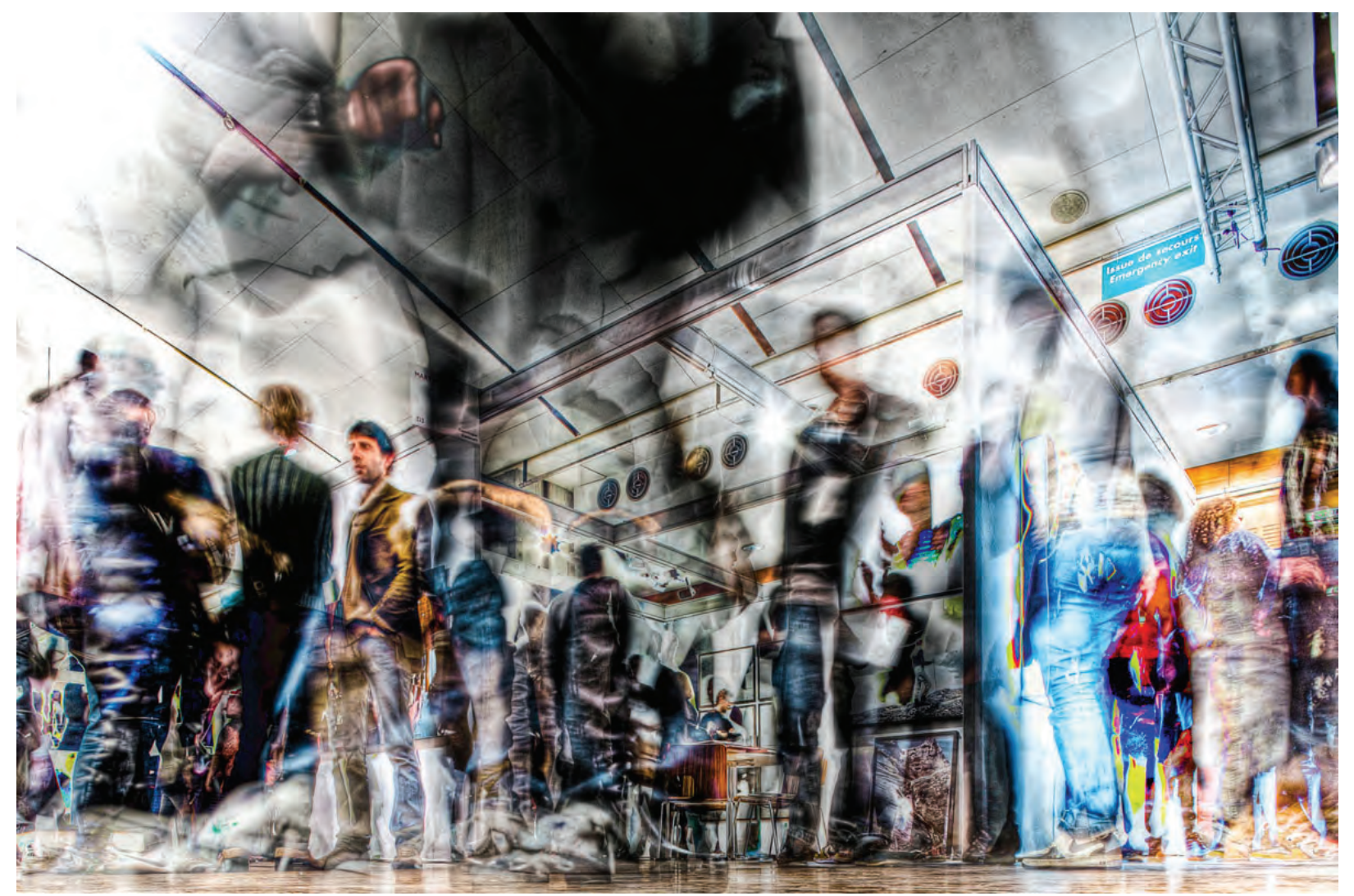

Figure 5: Aura \#2, Paris, Murat Germen, 2009

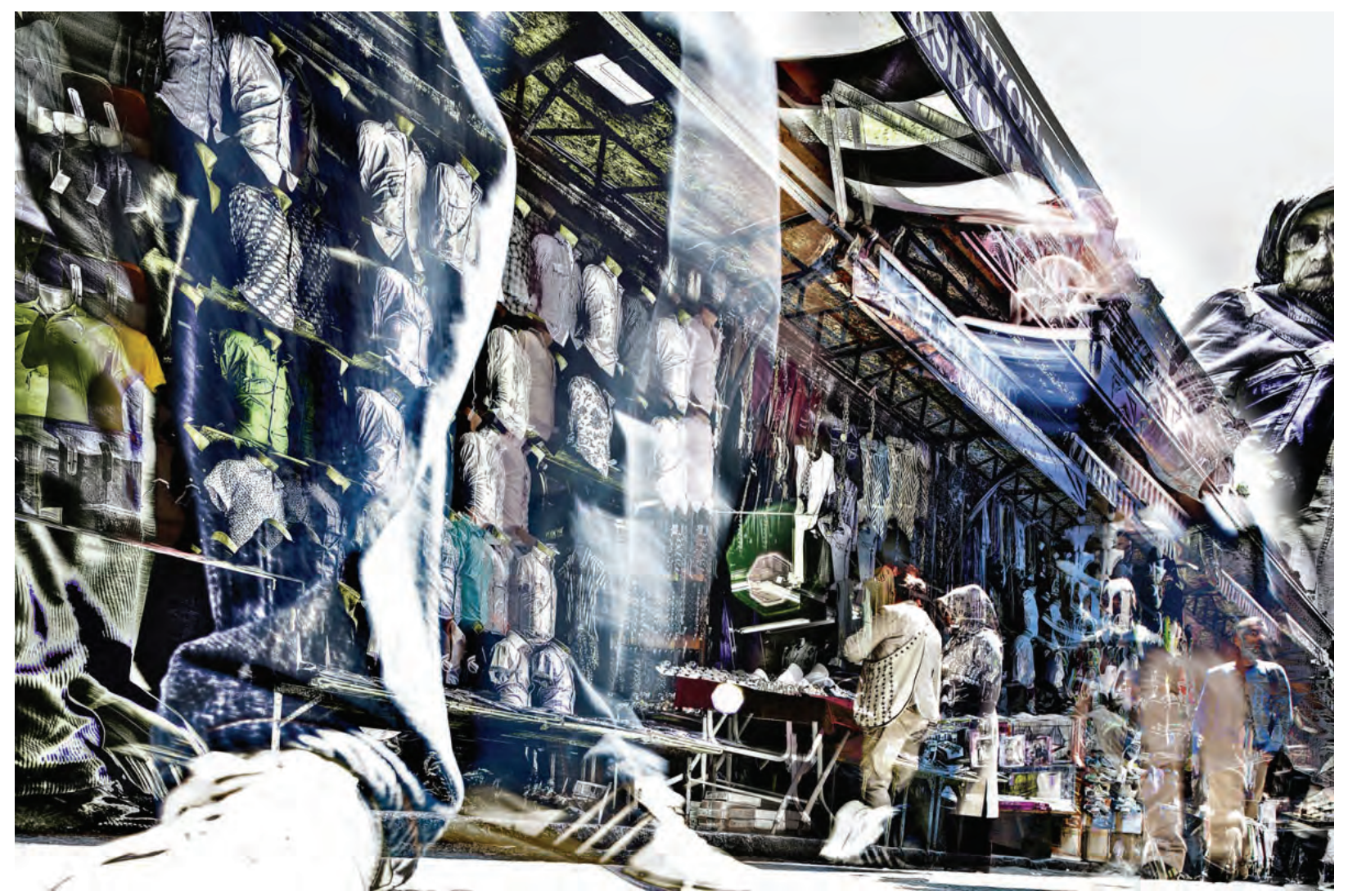

Figure 6: Aura \#3, Istanbul, Murat Germen, 2009 


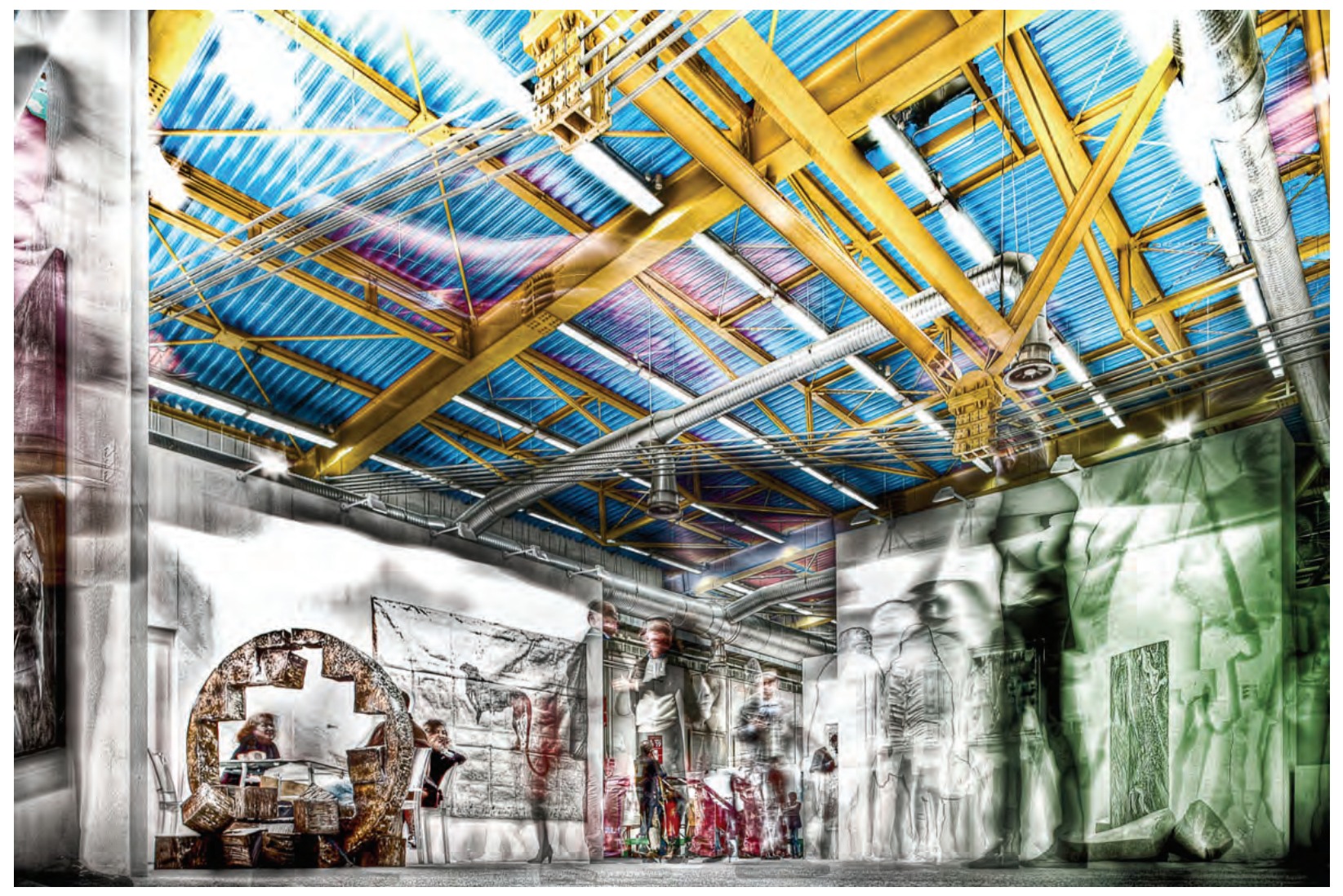

Figure 7: Aura \#22, Bologna, Murat Germen, 2009

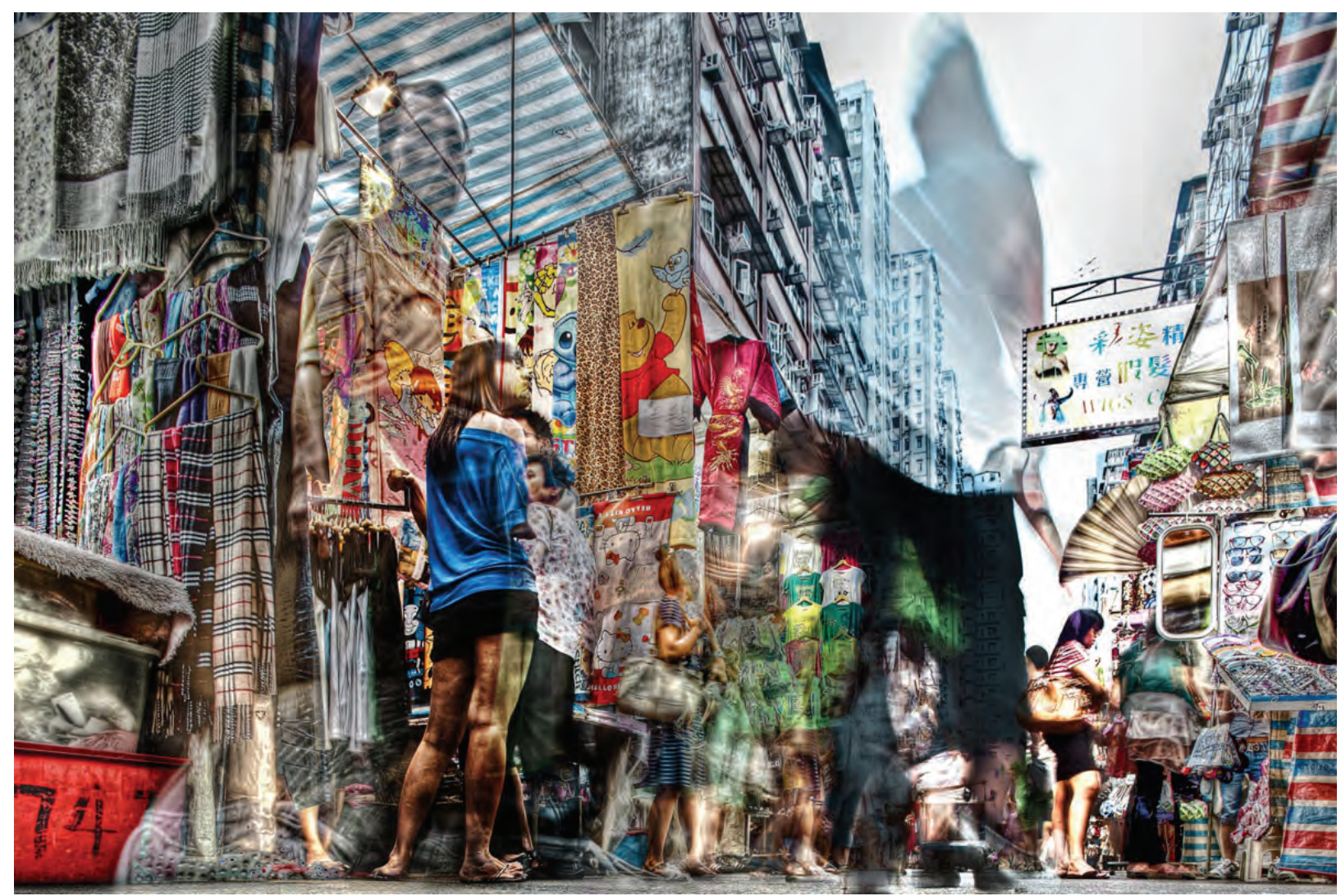

Figure 8: Aura \#18, Hong Kong, Murat Germen, 2009 


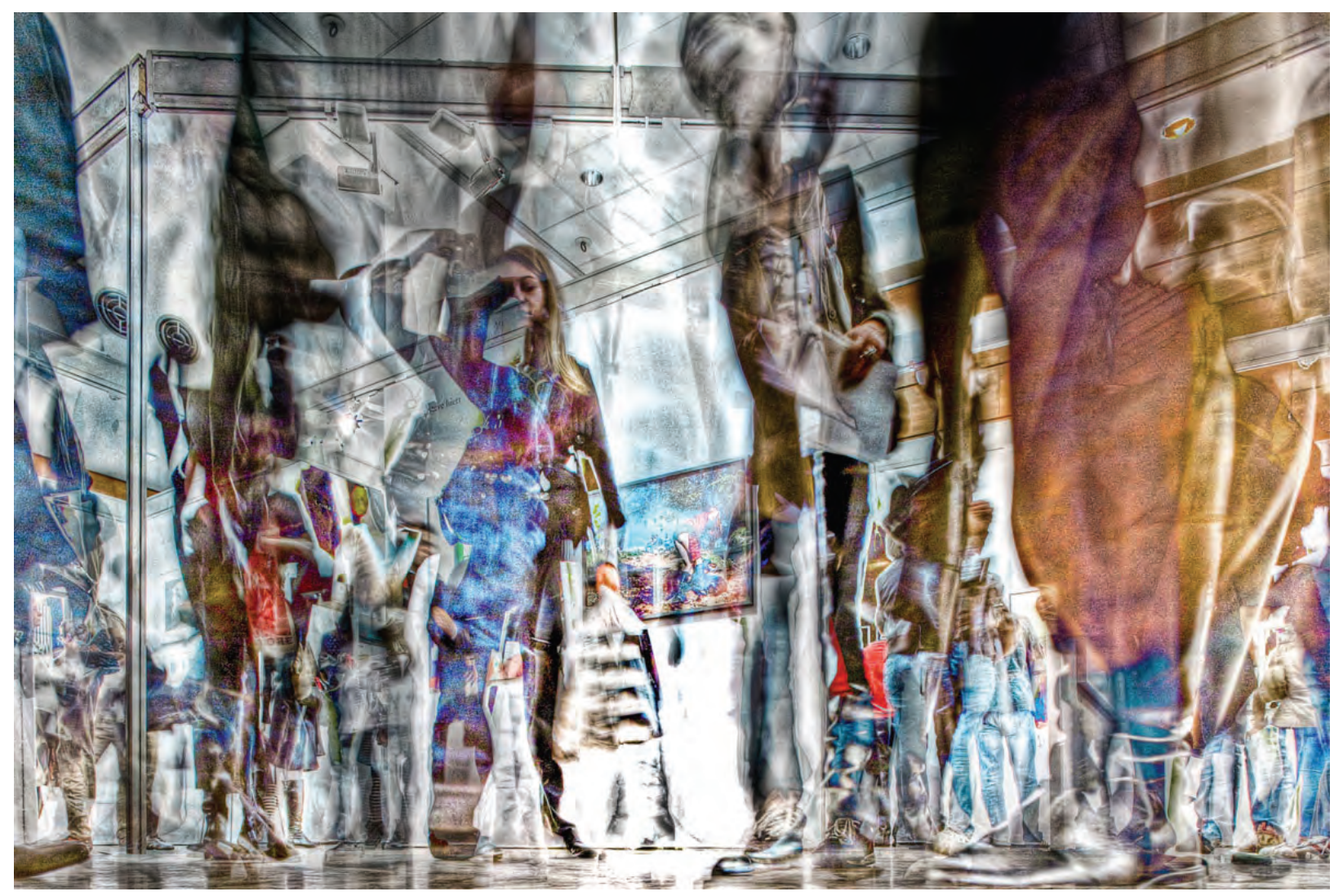

Figure 9: Aura \#27, Paris, Murat Germen, 2009

\section{REFERENCES}

Barthes, R. (1978) Image-Music-Text. Hill and Wang, New York.

Barthes, R. (1982) Camera Lucida: Reflections on Photography. Hill and Wang, New York.

Flusser, V. (2000) Towards a Philosophy of Photography. Reaktion Books, London.

Kempf, W. (2003) Constructive Conflict Coverage. A Social Psychological Research and Development Program. Conflict \& Communication Online.

http://www.cco.regener-online.de (12 March 2010).
Kingwell, M. (2006) The Truth in Photographs: Edward Burtynsky's Revelations of Excess. Steidl, Germany.

Manovich, L. (1995) The Paradoxes of Digital Photography.

http://www.manovich.net/TEXT/digital photo.html (18 March 2010).

Patin, T. and McLerran, J. (1997) Artwords: A Glossary of Contemporary Art Theory. Greenwood, Westport, CT.

Savedoff, B. E. (2000) Transforming Images: How Photography Complicates the Picture. Cornell University Press, Ithaca, NY. 